\title{
Bacterial Infection of Spine Instrumentation and Microbial Influenced Corrosion (MIC): Chicken or Egg
}

\author{
Reed Ayers*, Christopher Kleck, Mackenzie Miller and Evalina Burger \\ Department of Orthopedics, University of Colorado, United States
}

Received: November 03, 2017; Published: November 13, 2017

*Corresponding author: Reed Ayers, Ph.D, Department of Orthopedics, University of Colorado, School of Medicine, 12631 E. 17 th Avenue, B202 Room 4603, Aurora, CO 80045, United States, ORCID: 0000-0003-1646-251X; Email: Reed.Ayers@UCDenver.edu

\section{Opinion}

There is evidence that microbes including bacteria and macrophages are associated with in the presence biomedical alloys implants for orthopedic procedures [1-4]. The corrosion of metal alloys (A316L Surgical stainless steel; ASTM F136 ELI Ti6Al4V; ASTM F75/F1537/F799 CoCrMoC) in-vivo has also been well documented [5-8]. Proprionibacterium acnes as well as Staphylococcus Epidermis are considered sulfur reducing bacteria in the petroleum industry and have been found in petroleum stockpiles and pipelines $[9,10]$. These bacteria are associated with pipeline corrosion in oil fields and refineries [9]. In our own clinical experiences, we have noted a large number of spine metallosis cases and believe that the corrosion of implants and surgical site infections with P. acnes bacteria, or other sulfur reducing bacteria, are intimately connected in revisions and clinical infections. In our practice we observed an association between infection and implant corrosion leading to the initiation of a study examining revision of spinal instrumentation and patient outcomes. In patients who underwent spine instrumentation revision, who had grey or black stained tissues taken for culture in the OR and subsequent to the revision, we found 4 of 10 having P. acnes and Staph. epidermis present as a latent infection. A few patients showed clinical signs of infection, requiring subsequent drains and wash-out to clear all presence of bacteria. As early as 1999, P. acnes and Staph spp. were shown to be associated with orthopedic infections, where it was detected in $63 \%$ of sonicated samples taken from 120 patients receiving total hip revision [4]. As recently as 2016, P. acnes were highlighted as a possible contributor to post operative infections in orthopedic procedures [1]. These commensal skin dwelling microbes are anaerobic, sulfur reducing bacteria [11-13]. P. acnes, Staph. aureus and epidermis have been isolated as biofilm forming bacteria in orthopedics as well [3].

What this suggests is the presence of the implant provides a suitable substrate upon which the bacteria can colonize leading to latent infection. Additionally, the bacteria utilize the elements present in the instrumentation to sustain their metabolism while corroding the alloys. The presence of sulfur reducing bacteria and their biofilm formation on metals has been extensively studied in the petroleum industry. As noted, these bacteria are also found in other environments beyond our skin. Zhu et al. [9] identified Propionibacterium sp. strain V07/12348 and Propionibacterium sp. strain WJ6 and even E. coli in natural gas pipelines. Yoshida et al. [10] indentified P. acnes in crude oil samples in Japanese stockpiles as well as Staph sp. The crude tested included supplies from Arabia and Russia. The presence of Proprionibacterium sp. and staphylococci sp. would not be unexpected given the sulfur content of these supplies are 1-2wt\%. Conversely, sulfur reducing bacteria have been shown to be capable of residing upon and attacking titanium [14], as well as carbon steels [15]. This attack takes the form of acids such as H2S and proprionic acid created as the bacteria utilize sulfate, nitrate, nitrite, carbon dioxide, Fe3+, $\mathrm{Mn} 4+, \mathrm{Cr} 6+$, and other metal ions or bacterial waste products as electron acceptors for metabolism [16].

Thus, given the ubiquitous nature of these bacteria on the skin and deep dermal layers it is not surprising that latent infections can occur when implanted metal instrumentation is utilized in orthopedic procedures given they provide both a scaffold in the form of a place for biofilm to form and nutrients. Current explanations pertaining to the corrosion of spine biomedical alloys are focused upon galvanic/pitting/crevice, fretting corrosion. Galvanic corrosion of biomedical alloys, specifically Ti6Al4V (ASTM F-136ELI) and CoCrMoC (ASTM F75 and ASTM F1537) is not a real concern in modular constructs where theses two alloys are in intimate contact $[5,6]$. This is a well-studied phenomenon in spine instrumentation where the mixing of alloys is common, e.g. Ti6Al4V pedicle screw with a CoCrMoC tulip and an interlocking Ti6Al4V or CoCrMoC spine rod [17]. In galvanic corrosion, there are no apparent reactive pathways between Ti6Al4V and CoCrMoC. Similar to what is concluded $\mathrm{n}$ references 5 and 6 , the risk of galvanic corrosion in our experience is minimal based on the very close electronegative nature of the base alloy elements. Therefore, corrosion in instrumentation must be beyond galvanic corrosion. It has been our experience, that the corrosion coupling of Ti6Al4V and 
CoCrMoC alloys is predominantly a wear function where fretting between parts continuously exposes pristine substrate alloy to the surrounding body fluids (electrolyte), called tribocorrosion [7] In previous cases, we have observed the presence of particles or elements present on opposing surfaces present on all components, however, this phenomenon only appears to occur where fretting occurs. No intermetallic particles, suggesting some form of galvanic process are present.

All particles observed are oxides, CrxOy, TiOx, VO, MoO, and alumina based on EDS analysis. The physicochemical properties of the category 6 transition metals, $\mathrm{Cr}, \mathrm{Mo}, \mathrm{W}$, do not allow them to easily form any intermetallics with $\mathrm{Ti}, \mathrm{Al}$, or $\mathrm{V}$ at low temperatures [18]. The base elements, Co and $\mathrm{Ti}$, are soluble together and can form a compound through the use of arcmelting. Therefore, if one is to consider galvanic corrosion between these two alloys, the primary consideration must be the half-cell reaction releasing metal ions from oxides on either the Ti6Al4V or CoCrMoC surfaces as well as the electro-potential of the pure metal themselves. It is these released metal ions that act as positive charge carriers in the electrolyte. Both oxides are very stable. For example the major oxide Cr203 (the only stable form of chromium oxide in air at room temperature) has no reaction for its reduction in the body as that it is done under high temperatures $\left(>1200^{\circ} \mathrm{C}\right)$, pressures, or in aluminothermic reactions, e.g. explosive/combustion reactions. From our ongoing research the most likely explanation for the corrosion of alloys in spine is fretting wear and microbial induced corrosion. Each has sufficient energy to disrupt the passive oxides presence, allowing for corrosion of the substrate metals. Infection of comensual organisms is reasonable as these alloys provide a surface for protective biofilm formation and nutrients for bacterial growth.

\section{References}

1. Shiono Y, Ishii K, Nagai S, Kakinuma H, Sasaki A, et al. (2016) Delayed Propionibacterium acnes surgical site infections occur only in the presence of an implant. Sci Rep 12(6): 32758.

2. Jeremy L Gilbert, Shiril Sivan, Yangping Liu, Sevi Kocagöz, Christina Arnholt, Steven M Kurtz (2015) Direct In Vivo Inflammatory Cell-Induced Corrosion of CoCrMo Alloy Orthopedic Implant Surfaces J Biomed Mater Res A 103(1): 211-223.

3. Marta Ribeiro, Fernando J Monteiro, Maria P Ferraz (2012) Infection of orthopedic implants with emphasis on bacterial adhesion process and techniques used in studying bacterial-material interactions. Biomatter 2(4): 176-194.

4. Michael M Tunney, Sheila Patrick, Martin D Curran, Gordon Ramage, Donna Hanna, et al. (1999) Detection of Prosthetic Hip Infection at
Revision Arthroplasty by Immunofluorescence Microscopy and PCR Amplification of the Bacterial 16S rRNA Gene. Journal of Clinical Microbiology 37(10): 3281-3290.

5. Hassan Serhan, Michael Slivka, Todd Albert, S Daniel Kwak (2004) Is galvanic corrosion between titanium alloy and stainless steel spinal implants a clinical concern? The Spine Journal 4: 379-387.

6. Keun Taek Oh, Kyoung Nam Kim (2004) Electrochemical Properties of Suprastructures Galvanically Coupled to a Titanium Implant. Biomed Mater Res Part B: Appl Biomater 70(2): 318-331.

7. N Espallargas, C Torres, AI Muñoz (2015) A metal ion release study of CoCrMo exposed to corrosion and tribocorrosion conditions in simulated body fluids. Wear 332-333: 669-678.

8. Jacobs JJ, Gilbert JL, Urban RM (1998) Current Concepts Review, "Corrosion of Metal Orthopaedic mplants", J Bone and Joint Surgery 80(2): 268-282.

9. Xiang Y Zhu, John Lubeck, John J Kilbane (2003) Characterization of Microbial Communities in Gas Industry Pipelines. Applied and Environmental Microbiology 69(9): 5354-5363.

10. Nobuyuki Yoshida, Kazuhiro Yagi, Diasuke Sato, Noriko Watanabe, Takeshi Kuroishi, et al. (2005) Bacterial Communities in Petroleum Oil in Stockpiles. Journal of Biosceince and Bioengineering. 99(2):143-149.

11. Peter A Nielsen (1983) Role of Reduced Sulfur Compounds in Nutrition of Propionibacterium acnes. Journal of Clinical Microbiology 17: 276279.

12. James K Lithgow, Emma J Hayhurst, Gerald Cohen, Yair Aharonowitz, Simon J Foster (2004) Role of a Cysteine Synthase in Staphylococcus aureus. Journal of Bacteriology 186: 1579-1590.

13. Philip S Stewart, Michael J Franklin (2008) Physiological heterogeneity in biofilms. Nature Reviews, Microbiology 6(9): 199-210.

14. TS Rao, Aruna Jyothi Kora, B Anupkumar, SV Narasimhan, R Feser (2005) Pitting corrosion of titanium by a freshwater strain of sulphate reducing bacteria (Desulfovibrio vulgaris). Corrosion Science 47: 1071-1084.

15. BWA Sherar, IM Power, PG Keech, S Mitlin, G Southam, et al. (2011) Characterizing the effect of carbon steel exposure in sulfide containing solutions to microbially induced corrosion. Corrosion Science 53: 955960.

16. BJ Little, JS Lee (2009) Microbiologically influenced corrosion, (In) KirkOthmer "Encyclopedia of Chemical Technology" ( $5^{\text {th }}$ edn) John Wiley \& Sons (Publishers) Inc. Hoboken. New Jersey, US p. 1-38.

17. Reed A Ayers, Evalina Levina Burger, Christopher J Kleck, Vikas Patel (2015) Metallurgy of Spinal Instrumentation in "Advances in Metallic Biomaterials Technology" Mitsuo Niinomi, Takayuki Narushima, Masaki nakai (Eds.), Springer Series in Biomaterials Science and Engineering, Springer-Verlag Gmbh Heidelberg p. 53-70.

18. Riccardo Ferro, Adriana Sacconet (2008) Intermetallic Chemistry. Pergamon Materials Series, Elsevier, 2008.

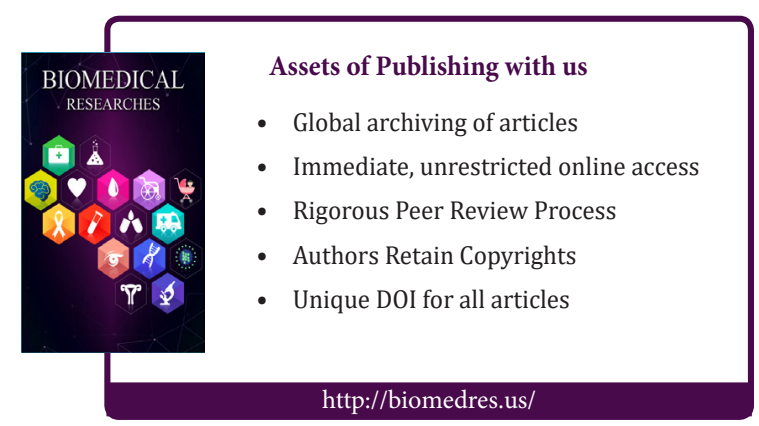

